\title{
A ENTREVISTA SEMIESTRUTURADA NA PESQUISA SOBRE A ELITE BANQUEIRA BRASILEIRA: NOTAS DE UM DIÁRIO DE CAMPO
}

Natália Frozel Barros ${ }^{1}$

RESUMO: O presente artigo analisa as implicações teóricas e metodológicas do uso, juntamente com outras, da técnica da entrevista semiestruturada no estudo empírico das elites, no nosso caso através da pesquisa de mestrado sobre a elite dos banqueiros brasileiros. Defendemos o uso da entrevista como um momento de análise social e de construção do objeto, para além de uma concepção puramente informativa da mesma. Fazemos isso, finalmente, analisando as resistências encontradas ao longo de 10 entrevistas com membros e antigos membros de uma organização patronal brasileira de banqueiros, assim como nossas estratégias e análises em face às dificuldades e limitações desse método.

Palavras-chaves: elites, entrevista semiestruturada, banqueiros.

RESUMEN: El trabajo analiza las implicaciones teóricas y metodológicas para el uso de la técnica de la entrevista semi-estructurada, en conjunto con otras técnicas, en el estudio empírico de las elites. Particularmente, a través de nuestra investigación de maestría sobre los banqueros brasileños, defendemos el uso de la entrevista como un momento de análisis social y de construcción del objeto, algo mas allá de una concepción puramente informativa de la entrevista. Analizaremos las resistencias de la parte de los 10 entrevistados miembros y antiguos miembros de una organización patronal brasileña de banqueros, y también las estrategias y análisis a las cuales recurrimos delante las dificultades y las limitaciones del método.

Palabras clave: elites, entrevista semi-estructurada, banqueros.

ABSTRACT: The following article focus on the theoretical and methodological implications of using semi-structured interviews within an empirical research on elite groups, notably the Brazilian financial elite. We shall defend a particular use of the interviews such as an experience to be socially analyzed and that contributes to round off the object of study. This kind of use goes beyond a pure informative conception of the interview technique. In order to do so, we shall point out the interviewee's resistances encountered along our 10 interviews with members and ex-members of a particular Brazilian bank organization. We will also line out our strategies and social analysis used to deflect the method's difficulties and limitations.

Keywords: elites, semi-structured interview, bank owners, bank managers.

\footnotetext{
${ }^{1}$ Mestranda em Ciência Política pela Université Paris-1 Panthéon-Sorbonne e em Sociologia política pela
} Ecole des Hautes Etudes en Sciences Sociales. Aluna bolsista da Ecole Normale Supérieure - Paris. 
A pesquisa de mestrado que vamos registrar aqui se situa na continuação de pesquisa sobre a teoria das elites no seu formato renovado e mais contemporâneo, o que se identifica nos escritos de Charles Wright Mills e na geração atual da Power Structure Research ${ }^{2}$. Na tentativa de operacionalizar empiricamente a análise de uma elite dominante no cenário atual brasileiro, diga-se de passagem mundial, fizemos um primeiro recorte em torno da categoria dos "banqueiros" no Brasil. Nossa problemática central é de responder ou ao menos de contribuir a uma resposta à seguinte questão: como aqueles que são em última instância reconhecidos como concorrentes econômicos se unem num esforço de cooperação organizada em volta de interesses coletivos comuns?3 ${ }^{3}$ No cruzamento de nossa problemática com a análise da elite banqueira brasileira, nos deparamos com a primeira dificuldade de pesquisa, isto é, como uma estudante sem contatos nas classes ${ }^{4}$ altas aborda uma elite altamente fechada em si mesma?

Privilegiamos assim, num primeiro momento, uma porta de entrada institucional ao escolher uma organização patronal brasileira de bancos (OPBB) 5 e seus diretores como objeto de estudo. "Num primeiro momento", pois, se tratando de uma perspectiva a partir da teoria das elites, a vasta literatura disponível atualmente mostra como nos altos círculos certos recursos aparentemente restritos à vida privada de seus atores são facilmente traduzidos em recursos na esfera profissional dos mesmos (USEEM 1984). Tendo isso em mente, tínhamos claro, desde o princípio da pesquisa, a importância de unir essas duas dimensões do comportamento das elites, união que nos pareceu somente possível através da análise dos atores inseridos e/ou relacionados mais diretamente com a organização patronal (OFFERLE 2009) dos banqueiros brasileiros. Além disso, sabíamos do déficit que pode surgir ao se restringir a análise à esfera meramente profissional desses atores políticos.

\footnotetext{
2 Autores como Michael Useem (1984), Beth Mintz e Michael Schwartz (1985) e outros. Ver também: Frozel Barros, N. "A investigação sobre a estrutura de poder: um levantamento bibliográfico", monografia defendida no final da graduação em Ciências Sociais da Unicamp sob orientação de Álvaro Bianchi.

3 Cabe ressaltar aqui que nossa questão se inicia com a palavra "como" e não "por que". Para além dos ganhos finais, queremos saber como essa elite concilia suas disputas internas dentro de uma organização coletiva.

4 O termo classe é aqui emprestado da tradição marxista do materialismo histórico e posto em relação com o que é identificado por alguns autores como nova perspectiva elitista: ver autores como Ralph Miliband e Charles Wright Mills; empresto termo de Danilo Martuscelli. Trata-se de uma tentativa de aproximar o conceito de uma classe alta, ampla e dominante à noção de elite enquanto grupo dominante no qual seus membros compartilham características comuns mais restritas ao grupo e atuação política mais homogênea. Utilizaremos menos frequentemente o termo classe aqui se comparado àquele de elite, pois nos concentraremos sobre o grupo restrito e bem delimitado da elite dos banqueiros brasileiros. Voltaremos mais adiante a essa questão teórica de fundo.
}

5 Afim de preservar a confidencialidade dos entrevistados, todos os nomes, de instituições e pessoas, aqui utilizados, são fictícios. A organização estudada será doravante mencionada como OPBB numa tentativa de acrônimo de "organização patronal brasileira de bancos". 
Antes de entrar nas implicações metodológicas de tal escolha e na consequente experiência de campo que vivemos, gostaríamos de fazer um breve parêntesis sobre a inspiração teórica que nos levou a "olhar" nosso objeto dessa maneira. Fazemos isso no intuito de deixar explícito o fato de que nossas escolhas teóricas estão intrinsecamente ligadas aos nossos procedimentos metodológicos. Nos deparamos, inicialmente, com a proposta de Adriano Codato e Renato Perissinotto (2008) de se construir um diálogo entre o elitismo (que distingue as estratégias políticas usadas por diferentes elites) e o marxismo (que identifica a dominação como um fator estrutural e a longo termo dentro do conceito de classe), operacionalizando o conceito de classe através do de elite.

Mesmo que essa proposta tenha sido feita dentro de um contexto sobre o estudo das elites políticas e a dominação de classe através do Estado, acreditamos que tal diálogo seja frutífero para além dessas ${ }^{6}$. Assim, ao invés de nos colocarmos a mesma questão desses autores, "em que medida as estratégias adotadas pelas diversas elites políticas podem ser vinculadas a uma base de classe?" (CODATO \& PERISSINOTTO 2008, p.18), do ponto de vista teórico, nos perguntamos como uma elite econômica, como a dos banqueiros, que detém um vínculo mais visível com a base de classe7, se organiza estrategicamente no que tange sua influência política sobre as elites políticas da cúpula governamental do Estado, mas também sobre a sociedade num sentido mais largo.

Para tanto, desdobramos empiricamente essa consideração teórica em dois outros momentos de questionamento. Precisaríamos analisar, inicialmente, como um setor capitalista concorrente se organiza politicamente numa forma de cooperação, o que quer dizer analisar a luta interna à elite que define como e quais interesses prevalecem dentro do grupo. Então, só em seguida, poderíamos nos perguntar como se dá o contato político entre a elite econômica dos banqueiros - organizada em torno de interesses específicos - e a elite política nacional. Responder de forma adequada a esses dois pontos numa pesquisa de mestrado nos pareceu além de nossas possibilidades, principalmente diante do fato que o pesquisador não reside no país onde se encontra seu objeto de estudo, o que, por sua vez, limitou o trabalho de campo. Temporalmente, o contato direto com os diretores da OPBB e com a organização em si ficou concentrado em apenas duas viagens ao Brasil, com respectivamente dois e um mês de duração. Diante das limitações que tal situação impôs ao aprofundamento das

\footnotetext{
${ }^{6} \mathrm{O}$ grande problema abordado por Codato e Perissinotto, num diálogo entre Nicos Poulantzas e a teoria das elites, em especial de Charles Wright Mills e Ralph Miliband, é o de que as elites políticas, que controlam os centros de poder do Estado, não necessariamente coincidiriam com a classe dominante, que tem seus interesses políticos garantidos dentro do Estado.

7 Pensamos aqui, em especial ao trabalho de François Chesnais (2004) sobre o peso atual do sistema financeiro mundial.
} 
entrevistas e da observação de campo, decidimos nos ater àquela primeira questão sobre a organização de concorrentes num "esforço" coletivo de cooperação.

Assim, iniciamos uma pesquisa de campo sobre e na OPBB, mas tomando em conta os atores políticos que aí encontramos. Mas quais são as implicações metodológicas ao aceitarmos a perspectiva do elitismo para tratar nosso objeto? Precisávamos, claramente, ter acesso aos atores que organizam os interesses da elite banqueira. Consequentemente, para além dos materiais institucionais públicos, das informações de arquivos (pessoais e institucionais) e das estatísticas sobre o setor bancário, demos uma atenção especial ao método da entrevista semiestruturada. Essa modalidade de pesquisa que permanece principalmente na ciência política como um “impensável metodológico", nas palavras de Philippe Bongrand e Pascale Laborier (2005, p.2), se mostrou essencial para nosso estudo, tendo em conta certas ressalvas necessárias à mesma. Para refletir sobre essa técnica metodológica, nos apoiaremos sobre uma corrente francesa de inspiração bourdieusiana que defende a importância da análise social da entrevista como parte da pesquisa sociológica e política.

\section{A entrevista sob a ótica da relação de dominação}

Primeiramente, a fonte da entrevista semiestruturada não dá conta de todo o campo, ou da "verdade" do campo (LAURENS 2004, p.123), e não deve ser o recurso único para a reflexão sobre o mesmo. Na verdade, e em segundo lugar, há de se reconhecer os limites do método da entrevista para, por exemplo, não cair num voluntarismo que limita a análise ao indivíduo e às suas motivações. Confrontar a narrativa do entrevistado com dados estatísticos, documentos de arquivo e, num sentido mais largo, com a estrutura na qual ele está inserido é uma operação essencial para dar conta do embate entre o voluntarismo e a estrutura (CODATO \& PERISSINOTO, 2008), ou seja, entre o sujeito de uma elite e a estrutura de dominação que o envolve.

Feitas as devidas ressalvas, justificamos nossa escolha pela entrevista semiestruturada com duas razões bem definidas. Inicialmente, queríamos atender a nossa necessidade de apreender tanto o lado profissional desses atores, quanto suas formações educacionais e sociais, como já explicamos. Ao contrário da experiência vivida na França, onde informações sobre o percurso profissional e educacional das elites nacionais são relativamente públicas através do Who's Who, que abrange diferentes tipos de elites, e do Bottin mondain, mais restrito a uma burguesia aristocrática, no Brasil tais informações se encontram espalhadas e, algumas vezes, inacessíveis ao pesquisador. Assim, a fonte da entrevista nos serviu em muitos 
momentos como indicador de onde buscar informações sobre o perfil e os grupos/associações dos entrevistados e, em último caso, como fonte primária quando a documentação era inacessível.

Finalmente, a entrevista foi também uma fonte essencial para dar conta do dia a dia de uma organização patronal, o que nos disse muito sobre os conflitos internos existentes na OPBB, mesmo que oficialmente escondidos sob o véu da "política do consenso" que muitos dos nossos entrevistados defenderam. Assim, ouvimos narrativas sobre como os empregados driblam as disputas internas em suas rotinas de trabalho, sobre certas convenções não oficiais, mas forçosamente seguidas e coletivamente reconhecidas no seio da organização, enfim, obtivemos acesso a informações impossíveis de serem encontradas em um documento oficial da organização.

Entretanto, para além de um caráter puramente informativo, a experiência das entrevistas semiestruturadas nos deixou claro como o contato com um membro de uma elite está longe de constituir um momento de imparcialidade social entre o entrevistado e o entrevistador. Essa constatação nos demandou, consequentemente, uma certa autorreflexão crítica e posterior sobre o momento da entrevista, uma prática defendida por pesquisadores como Sylvain Laurens (2004), Michel Pinçon e Monique-Charlot Pinçon (1991), Chamboredon et al (1994). Antes de mais nada, a maioria de nossas experiências de entrevista ${ }^{8}$ deixaram palpável o que encontramos muitas vezes nos artigos e manuais de metodologia: em geral, as entrevistas com atores sociais das classes altas são marcadas por uma relação de dominação do entrevistado sobre o entrevistador. (PINÇON \& PINÇON-CHARLOT 1991).

No quadro do nosso trabalho de campo, são vários os sinais de dominação que percebemos ao longo da pesquisa. Podemos citar aqui alguns, tal qual o fato da entrevistadora ser uma estudante, um recurso pessoal, ou na gramática de Pierre Bourdieu (1979), um capital simbólico visivelmente fraco na hora de se negociar a realização de uma entrevista com o diretor geral da organização dos banqueiros. Para nossa primeira entrevista dentro da OPBB e coincidentemente com o diretor geral, levamos um mês e meio de tentativas, período marcado por inúmeros telefonemas à instituição, 18 cartas diretamente enviadas aos diretores e duas visitas pessoais à sede em São Paulo. Inclusive, passar do atendimento telefônico da secretaria da OPBB se tornou um real desafio nesse um mês e meio e, quando finalmente conseguimos marcar uma data, essa foi marcada para dali um mês.

Durante a entrevista, outros sinais como a possível diferença de vestimenta, a distância social do meio do entrevistador para com o ambiente da entrevista ou não

\footnotetext{
${ }^{8}$ Entre junho 2010 e dezembro 2010, entrevistamos um total de 10 diretores, sendo 1 diretor executivo/banqueiro, antigo representante da CEF, o diretor geral e 8 diretores-quadros, empregados da OPBB.
} 
saber se comportar segundo os códigos corporais do entrevistado são fatores que continuam a reafirmar essa dominação, podendo mesmo influenciar no tratamento e na seriedade dada ao pesquisador pelo entrevistado. Na nossa experiência de campo, nos chamou a atenção que, em mais de uma ocasião durante a conversa, o diretor corta a entrevista no meio ou avisa de antemão do pouco tempo disponível, confirmando a observação de Pinçon e Pinçon-Charlot sobre sua pesquisa sobre a burguesia tradicional francesa, "esse tempo raro e precioso que lhe é sacrificado coloca o pesquisador na posição de devedor, o que reforça ainda mais a distância entre o entrevistador e o entrevistado" (1991, p.130).

Reconhecer essa possível e provável relação de dominação na hora da entrevista pode vir a preparar o pesquisador para esses golpes simbólicos que podem desestabilizar o andamento da conversa. Enquanto em uma entrevista com um antigo vice-presidente da Caixa Econômica Federal (CEF) e diretor executivo da OPBB pudemos alongar a conversa para mais de quatro horas, cobrindo com calma e em detalhes nosso pré-questionário, em duas outras ocasiões com os diretores-quadros da organização nos encontramos no meio da entrevista de menos de meia hora tendo que priorizar algumas perguntas em detrimento de outras, o que pode vir a ser uma lacuna na hora de comparar as respostas dos entrevistados.

Entretanto, para além das precauções (roupas adequadas, definir o horário de antemão e etc.) que podemos tomar previamente ao reconhecer a relação de dominação numa entrevista com um membro de uma elite, esse desnivelamento acarreta consequências de outra ordem: nessa relação de dominação invertida - quando comparada com entrevistas com membros das classes mais baixas em face a um pesquisador com título acadêmico e etc. -, pudemos encontrar algumas vezes fortes efeitos de resistência da parte do entrevistado. Abordaremos em seguida três delas, tentando destacar as implicações de cada uma para nossa análise e, quando possível, nossas estratégias para driblá-las.

Primeiramente, em especial com os entrevistados ainda na ativa (a grande maioria), tivemos que enfrentar discursos em alguns casos já preparados, em outros profundamente propagandistas da instituição e, em geral, altamente generalistas. Ou seja, principalmente nesse momento da OPBB em que ela se engaja numa recente política de responsabilidade social, a figura do entrevistador foi percebida por alguns como um vetor de propaganda social da organização. Consequentemente, nos encontramos com o desafio de direcionar esse discurso inicial para uma narrativa do dia a dia dos profissionais, insistindo várias vezes no que seria um dia típico do mesmo, com quem ele tem mais contato direto, etc. Entretanto, a entrevista se mostrou muito mais proveitosa quando dedicávamos os primeiros minutos da mesma a ouvir esse 
discurso já engatilhado pelos diretores. Somente num segundo momento começávamos a colocar as questões que havíamos preparado.

Outro recurso para conter esse tipo de discurso foi o uso de dados oficiais como estatísticas, declarações públicas, discursos registrados, enfim, documentos com os quais confrontávamos o discurso do entrevistado, uma sugestão de Laurens (2004) e que se mostrou de grande valor. Analisando esses momentos de resistência e principalmente a reação dos entrevistados quando confrontados com os documentos públicos, pudemos em alguns momentos analisar a distância entre o discurso institucional da OPBB e as práticas e percepções dos entrevistados. Por exemplo, na conversar com um diretor sobre o Conselho de Autorregulação, formado "oficialmente" pela sociedade civil, quando questionado sobre um de seus membros, ele mesmo faz a crítica e nos dá sua interpretação, diferente do discurso oficial.

-E há outros (membros) que se beneficiariam um pouco dessa regulação bancária, não? Como o Serasa, por exemplo.

Mas o Jorge não é mais do Serasa, ele foi do Serasa.

-Mas na época em que ele foi contratado ele fazia parte do Serasa, segundo essa entrevista aqui. (sem nem verificar a entrevista, ele responde)

É... quando foi contratado sim, mas ele saiu logo depois com a venda do Serasa. É uma crítica que se faz ao modelo sim, essa participação da sociedade civil, que não representa a sociedade civil, você precisa melhorar. Mas no início foi útil.

-Foi útil por que não atrapalhava?

É, nos deu espaço para construir alguma coisa sem nenhuma trava.

Uma segunda resistência significativa foi da parte de alguns entrevistados em falar sobre alguns aspectos de sua vida pessoal, desde informações sobre a profissão de seus pais, até em contar como exatamente eles foram contratados pela OPBB. Na entrevista com outro diretor da organização, essas duas dificuldades aqui listadas se combinaram. Mais de uma vez o entrevistado parava de falar dele para retornar ao discurso de responsabilidade social da OPBB. Como resultado, sua trajetória pessoal se encontra fracionada em vários momentos da entrevista, o que, por sua vez, ocasionou algumas lacunas importantes na hora de reconstruí-la. Visto que a entrada ao campo se deu através da figura institucional da OPBB, uma tal ingerência sobre aspectos pessoais não foi bem compreendida por alguns, mesmo que o interesse pelo percurso pessoal desses tenha sido anunciado, como o foi, a todos de antemão. Como lembrado por Chamboredon et al (1994, p.116), fica a dificuldade de dar conta da multiposicionalidade de um agente que transborda sua faceta profissional.

-Agora eu queria ouvir um pouco sobre você. De onde você veio. Quero dizer, onde você nasceu, sua idade, qual a profissão dos seus pais..

Eu venho... A minha vida inteira foi em banco. Minha carreira toda foi em banco. (continua falando da carreira profissional) 
Essa resistência faz parte do discurso da "apresentação-de-si" (CHAMBOREDON et al 1994, p.118) através da figura profissional, aquela ligada à OPBB, mesmo que, em alguns casos, tenhamos observado como o profissional muitas vezes não é puramente profissional. Por exemplo, pudemos averiguar que a rede de contatos não só profissional, mas pessoal de um dos diretores-quadros - dada sua herança familiar nos altos meios do exercício do direito paulistano - influenciou, como ele mesmo admite, na sua contratação. Geralmente, nesse ponto da entrevista, nos deparamos com dois tipos claros de reação, aquela em que o entrevistado praticamente começa uma nova entrevista, e aquela em que temos que relançar a mesma pergunta, ou perguntas mais específicas, várias vezes antes de uma resposta ou de finalmente desistirmos. Sylvain Laurens (2004) faz uma sugestão em face a esse tipo de resistência, a qual infelizmente não utilizamos pela falta de tempo e pelas dúvidas éticas aí presentes. $\mathrm{O}$ cientista político francês propõe uma conversa informal mais ao final da entrevista, onde ele encontra os entrevistados mais relaxados ao considerarem que o gravador já foi desligado. Permanece, porém, aberta a questão da ética em se utilizar ou não essas informações.

Finalmente, a maior dificuldade que enfrentamos foi a recusa total dos diretores-quadros e do ex-diretor-banqueiro da $\mathrm{CEF}$, esse com maior contato direto com os outros diretores-banqueiros, de nos proporcionar uma apresentação para um desses últimos. Nossa análise posterior dessa reação negativa generalizada se assemelha muito à observação de Pinçon e Pinçon-Charlot (1991) sobre a importância do "ritual de apresentação" para atingir os escalões mais altos dessa elite economicamente dominante. Situarmo-nos socialmente longe de uma tal elite e entrarmos no campo através da porta institucional da OPBB são fatos que, aliados à falta de indicações pessoais, criou limitações claras para explorar as esferas mais altas da própria organização, o que interpretamos como uma evidência do círculo altamente fechado que caracteriza a elite dos banqueiros.

A partir desses três exemplos pontuais de dificuldades e das consequências que eles podem gerar para a análise científica, gostaríamos de defender aqui a necessidade de se processar o material coletado através de uma análise das condições da entrevista, reconhecendo os limites da mesma e inclusive ressaltando as resistências encontradas por parte do entrevistado. Enfim, em nossa experiência com os diretores da OPBB, buscamos lançar mão da entrevista semiestruturada para além de um recurso informativo-técnico, as condições e a experiência da entrevista entram posteriormente na análise do próprio objeto (LAURENS 2004, p.117). O contato direto com os atores estudados durante a prática da entrevista nos permitiu tanto realizar num segundo 
momento a análise sociopolítica da entrevista, quanto engendrou desafios maiores e a longo prazo para a continuação da pesquisa.

Ao assumir que a experiência da entrevista constitui um momento de dominação e, portanto, de parcialidade social tanto do entrevistador em relação ao entrevistado, quanto no sentido inverso, aperfeiçoar a entrevista com recursos e estratégias que tentam ultrapassar as resistências dos entrevistados permanece um desafio no sentido de se aperfeiçoar o próprio objeto estudado durante o contato da entrevista. Principalmente durante a mesma, mas também durante a redação, nos pareceu importante fazer uma análise crítica sem tornar impossível a volta ao campo para si mesmo e para outros. No nosso caso, em particular, um de nossos entrevistados pediu uma cópia final da dissertação: como proceder nesse caso se pretendemos voltar posteriormente e aprofundar nossa pesquisa?

Apesar de não termos, todavia encontrado uma resposta definitiva para tal questão, reconhecemos que a volta ao campo e a futura acessibilidade ao mesmo estarão condicionadas ao retorno que o entrevistado pede do entrevistador. Não obstante, em se tratando de uma organização relativamente pequena e de um grupo nacional seleto, os artifícios de confidencialidade passíveis de serem usados ao longo da redação não se demonstrarão tão confidenciais uma vez apresentados dentro do meio estudado. Há de se considerar, ainda, o trabalho final que se busca numa tal empreitada, em outras palavras, uma análise crítica do objeto. Assim, abrir mão de certas considerações pela volta ao campo pode ser igualmente analisado como um momento de dominação do entrevistado sobre o entrevistador. Momento que ultrapassa o intervalo da entrevista alcançando, inclusive, àquele da produção final da análise sociopolítica proposta pelo pesquisador.

\section{A entrevista para além da informação: outras considerações}

Finalmente, gostaríamos de encerrar apresentando mais algumas das nossas conclusões preliminares sobre a organização dos interesses dos banqueiros através da $\mathrm{OPBB}$, as quais estão intimamente ligadas às nossas entrevistas semiestruturadas. Primeiramente, apesar de não termos explorado diretamente, através das entrevistas, os perfis dos diretores banqueiros, em muitos momentos o relato dos diretores-quadros nos proporcionaram informações importantes sobre àqueles primeiros. Em particular, ao entrevistar um terceiro diretor-quadro, percebemos que suas funções diárias de programação de cursos, seminários e congressos se concentram num trabalho de logística em nome da instituição. Entretanto, a partir do momento em que o entrevistado busca uma personalidade econômica ou política para participar 
extraordinariamente em algum dos eventos, é a agenda pessoal do presidente da OPBB (diretor-banqueiro) que é colocada à disposição da organização. Um exemplo claro dos atributos resultantes de uma vida tanto profissional, quanto pessoal, próprios ao indivíduo e que são tornados disponíveis ao coletivo através de seu posto de presidente.

-E como você faz para encontrar essas pessoas que você não tem através do contato da OPBB de longa data?

Ou é indicação de alguém. E aí alguém abre a porta pra gente.

-Nesse caso você acha que a agenda pessoal dos banqueiros ajuda bastante?

Ajuda. Ajuda.

-Então o convite passaria por eles ao invés de pela OPBB?

É, algumas vezes sim.

-E você acredita que tenha diferença entre ser pelo presidente do banco X e pela OPBB?

Tem. Ele é o presidente do.., não é nem por ser presidente do banco, na verdade, a agenda do presidente da OPBB faz toda a diferença.

-Então seria mais o presidente da OPBB ...

É.

- ...do que dos outros bancos.

Não, é... Isso até já aconteceu, mas menos, a gente não explora, né? Com isso a gente toma muito cuidado, por ser restrito a cada banco. Agora, a agenda do presidente a gente explora sim. É um dos papéis dele. Por exemplo, este ano, nós fizemos o seminário de Economia com o BNDES e nós trouxemos o Luciano Coutinho. Só conseguimos trazer o Luciano Coutinho porque o Carlos Moraes (*presidente) pegou o telefone e ligou. Senão jamais.

Em segundo lugar, já nos era claro, antes mesmo das entrevistas, como a cadeira da presidência da organização se limitava aos representantes dos maiores bancos entre o grupo. Efetivamente, dois de nossos entrevistados-quadros identificaram de forma espontânea a existência do que eles chamam de um "rodízio fechado" e de um "revezamento não declarado" (essa última expressão falada em sussurros durante a entrevista) para a presidência da OPBB: um tipo de regra não dita, mas reconhecida e seguida por todos. Ao cruzarmos tais observações com a análise da presidência durante os últimos vinte anos (1991-2010) e com a entrevista com um exdiretor executivo, antigo representando da CEF na organização, esse dado se tornou ainda mais complexo e revelador da política interna à organização. Não basta afirmar que são os bancos oligopolistas que dominam as esferas mais altas da OPBB, as diferentes clivagens que encontramos dentro da mesma (público $x$ privado, capital nacional $x$ internacional, bancos grandes, médios e pequenos) criam certas tensões, perceptíveis em alguns trechos da fala do ex-vice-presidente da CEF: 
Sobre sugerir algum nome para a presidência: "Eu não sugeria, porque eu não era do mercado e eu era o banco público e eu sempre via isso porque a direção tinha que ser privada, não pode ser pública. Senão era vista como um braço do governo. Se eu fosse (presidente), evidentemente, eu faria o trabalho do governo na OPBB e não dos interesses privados. Então tem que ser privada".

Ou ainda sobre os bancos de capital estrangeiro: “. -Existe realmente essa reticência em relação aos bancos de capital estrangeiro?

Eu seria contra. Se me consultarem..., eu? Enquanto delegação brasileira, não pode ter representação de estrangeiro. Não faz sentido. Então sobra pouco, não? (para o posto de presidente)".

Fica clara a percepção do entrevistado de que a OPBB consiste numa organização "do mercado", o que reflete diferenças de tratamento à participação dos bancos públicos, embora sejam essenciais, visto o tamanho de bancos como o Banco do Brasil e a CEF, diante da preponderância dos oligopólios privados9. O que, por sua vez, gera uma contradição na própria fala do entrevistado se tomamos em conta a presidência atual ocupada por banqueiro ligado ao capital estrangeiro. Quando questionado sobre a contradição, o antigo vice-presidente da CEF responde:

"O Banco do Brasil e a Caixa não assumiam presidência, é o certo, pelo menos segundo a minha visão. Os estrangeiros, ninguém queria. O Carlos Moraes é do Banco X, mas ele é uma liderança, ele fala todo articulado, falava bem, tem talentos, tem empatia, então, tem um perfil profissional impecável".

A distância entre o discurso racional de um representante de um banco público e a aceitação de uma figura do capital estrangeiro representa um momento de suspensão parcial de um principio racional (no sentido dado pela teoria da escolha racional), que teoricamente guiaria o comportamento do nosso entrevistado. Trata-se, efetivamente, de um momento no qual um certo predomínio do traço de grande oligopólio bancário, travestido aqui na alta reputação do presidente ${ }^{10}$, predomina na forma do representante "aceitável", mesmo se de banco estrangeiro. O que, por sua vez, nos remete à definição de Emmanuel Lazega (2009) de como a cooperação entre concorrentes engendra "um momento de suspensão racional em relação à racionalidade do mercado": se suspende parcialmente a concorrência em favor de uma solidariedade coletiva forçada ou não, passível de ser encontrada de forma mais clara no seio da OPBB'11.

\footnotetext{
9 Desde sua fundação, nenhum banco público nunca presidiu a OPBB. Fonte: Livro de 40 anos.

10 Podemos traduzir essa reputação tanto pelos "pertencimentos" a diferentes círculos e instituições altamente valorizadas socialmente, como mostra Useem (1978) em sua análise das escolas e clubes privados dos principais CEOs norte-americanos e ingleses, quanto através da perspectiva de violência simbólica dos diferentes tipos de capitais concentrados na figura do presidente, retomando aqui o método posicional de Pierre Bourdieu (1979).
} 


\section{Balanço geral}

Ao considerar a entrevista semiestruturada como parte da reflexão científica, abrimos a pesquisa a um novo momento de análise com grande potencial de contribuição ao delineamento e ao conhecimento de nosso próprio objeto, uma vez que as considerações anteriormente apresentadas aqui, por exemplo, nos forneceram indicações empíricas relevantes. Seja a "suspensão racional em relação à racionalidade do mercado", seja a relação de dominação ou como certos atributos pessoais de alguns atores são intercambiáveis com o meio profissional do grupo, tais considerações colocam em evidência certas características recorrentes dentro de um grupo fechado da classe alta, de uma elite bem definida.

Apresentando aqui as justificativas teórico-metodológicas e o andamento de nossa pesquisa de mestrado, esperamos contribuir à reflexão crítica sobre um ainda "impensável metodológico" (2005), mas de grande potencial para as pesquisas sociológicas e políticas atuais das elites. Seu potencial reside principalmente no fato de assumirmos a técnica da entrevista semiestruturada como um momento a ser analisado e inserido de forma crítica na redação final e não somente como uma ferramenta puramente informativa.

\section{REFERÊNCIAS BIBLIOGRÁFICAS}

BONGRAND, P. e LABORIER, P. 2005. L'entretien dans l'analyse des politiques publiques : un impensé méthodologique ? Revue Française de Science Politique, Paris, v. $55, \mathrm{n}^{\circ} 11$, pp. $73^{-111}$, fevereiro.

BOURDIEU, P. 1979. La distinction : critique sociale du jugement. Paris, Editions de Minuit.

CHAMBOREDON, H.; PAVIS, F.; SURDEZ, M. E WILLIMEZ, L. 1994. S’imposer aux imposants. A propos de quelques obstacles rencontrés par des sociologues débutants dans la pratique et l'usage de l'entretien. Genèses, Paris, nº 16, pp. 114-132, junho.

CHESNAIS, F. 2004. La finance mondialisée: racines sociales et politiques, configuration, conséquences. Paris: La découverte.

CODATO, A. e PERISSINOTTO, R. 2008. Elitismo versus marxismo? Por uma agenda empírica de pesquisa. Paper apresentado no $32^{\circ}$ Encontro Anual da ANPOCS, Caxambu - MG, outubro de 2007. Disponível em : [http://www.persee.fr/articleAsPDF/genes_11553219_1991_num_3_1_1050/article_genes_1155-3219_1991_num_3_1_1050.pdf].

\footnotetext{
${ }^{11}$ Essa dominação oligopolista privada se mostrou, por fim, muito mais abrangente que o posto da presidência, a mesma lógica de dominação é verificável em práticas como decidir na reunião executiva quem vai estar presente nas reuniões com representantes políticos do BC, Ministérios federais, Receita Federal e etc. Fonte: pautas das reuniões da direção executiva da OPBB.
} 
LAURENS, S. 2004. "Pourquoi" et "comment" poser les questions qui fâchent ? Réflexions sur les dilemmes récurrents que posent les entretiens avec des imposants. Genèses, Paris, v. 4, nº 69, pp. 112- 127, dezembro.

LAZEGA, E. 2009. Théorie de la coopération entre concurrents : organisations, marchés et analyse de réseaux. In : STEINER, P. e VATIN, F (org.). Traité de sociologie économique. Paris: Presses Universitaires de France.

MARTUSCELLI, Danilo E. Elites e classe dominante: notas sobre o marxismo inspirado na teoria das elites. Revista Outubro, n. 18, p. 247-275, 2009.

MINTZ, B. e SCHWARTZ, M. 1985. The power structure of American business. Chicago: University of Chicago.

OFFERLE, M. 2009. Sociologie des organisations patronales. Paris: La découverte.

PINÇON, M. e PINÇON-CHARLOT, M. 1991. Pratiques d'enquête dans l'aristocratie et la grande bourgeoisie : distance sociale et conditions spécifiques de l'entretien semidirectif. Genèses, v. 3, $\mathrm{n}^{\circ}$ 3, pp. 120-133, março.

USEEM, M. 1984. The Inner Circle : large corporations and the rise of business political activity in the U.S. and U.K. New York : Oxford University Press. 